\title{
Current understanding of the bi-directional relationship of major depression with inflammation
}

\author{
Berhane Messay, Alvin Lim and Anna L Marsland*
}

\begin{abstract}
Consistent evidence links major depression and its affective components to negative health outcomes. Although the pathways of these effects are likely complex and multifactorial, recent evidence suggests that innate inflammatory processes may play a role. An overview of current literature suggests that pathways between negative moods and inflammation are bi-directional. Indeed, negative moods activate peripheral physiologic mechanisms that result in an up regulation of systemic levels of inflammation. Conversely, peripheral inflammatory mediators signal the brain to affect behavioral, affective and cognitive changes that are consistent with symptoms of major depressive disorder. It is likely that these pathways are part of a complex feedback loop that involves the nervous, endocrine, and immune systems and plays a role in the modulation of peripheral inflammatory responses to central and peripheral stimuli, in central responses to peripheral immune activation and in the maintenance of homeostatic balance. Further research is warranted to fully understand the role of central processes in this feedback loop, which likely contributes to the pathophysiology of mental and physical health.
\end{abstract}

Keywords: depression, negative affect, inflammation, inflammatory markers, cytokines

\section{Background}

Evidence shows an association of major depression with increased risk for adverse physical health outcomes. Indeed, depression, whether assessed as a continuum of symptoms or as the presence of a clinical syndrome, predicts the incidence and progression of diseases of aging, including cardiovascular, metabolic and neurodegenerative diseases, as well as all-cause mortality [1-3]. Given the burden of these physical illnesses, it is not surprising that affective symptoms and disorders are more prevalent among the medically-ill than the general population $[4,5]$, raising the possibility that associations between affective disorders and physical health are bidirectional in nature. It is also likely that lifestyle choices contribute to poorer health among individuals with depression [6]; however, to date, evidence suggests that behavioral factors contribute only minimally to depression-related variability in health risk. Thus, other

\footnotetext{
* Correspondence: marsland@pitt.edu

Department of Psychology, University of Pittsburgh, 3213 Sennott Square, 210 S. Bouquet St., Pittsburgh, PA 15260, USA
}

mechanisms must also be operating. Accumulating evidence suggests that the immune system may play a role.

\section{Main Text}

Early studies show an association of depression with the down-regulation of functional parameters of the immune system (for example, decreased ability of NK cells to destroy tumor cells [7]). However, this immune suppression is not as 'global' as initially proposed. Indeed, recent attention has focused on the activation of innate, non-specific inflammatory mechanisms that also accompany depressed mood [8]. These differential immune responses to negative mood have been interpreted within an evolutionary context as a down-regulation of processes that take time and energy in favor of an up-regulation of processes that are immediately available to defend the organism [9]. Although adaptive and of potential health benefit in the short-term, growing evidence shows that chronic elevation of inflammation plays a role in the pathogenesis and course of numerous age-related physical health conditions, possibly 
contributing to the co-morbidity of depression with chronic physical illness [10].

The inflammatory response is a non-specific immune reaction that is initiated when monocytes/macrophages are activated by pathogens or tissue damage to release pro-inflammatory cytokines, such as interleukin (IL)-6, IL- $1 \beta$, and tumor necrosis factor (TNF)- $\alpha$. These cytokines initiate a local and systemic inflammatory response, which includes the hepatic synthesis and release of acute phase proteins, such as $\mathrm{C}$-reactive protein (CRP) and fibrinogen [11]. Peripheral pro-inflammatory cytokines also signal the brain, resulting in symptoms of sickness that typically accompany infectious disease, such as fever, depressed affect, suppressed appetite, increased sleep, and cognitive deficits [12,13].

Circulating levels of pro-inflammatory mediators are widely accepted as a marker of systemic levels of inflammation. However, caution should be taken in assuming these inflammatory mediators are immune-derived as many cells produce these signaling proteins, including adipocytes and endothelial cells [14]. Regardless of source, circulating levels of IL-6 are relatively stable over extended periods [15], are positively related to age [16], and predict risk for a range of age-associated diseases [17]. Consistent evidence also shows that individuals with major depressive disorder have higher levels of circulating markers of inflammation than nondepressed individuals. For example, two recent metaanalyses concluded that increased plasma levels of TNF$\alpha$, IL-6, IL-1, and CRP accompany major depression $[18,19]$.

Available data suggest that relationships between proinflammatory cytokines and depressed mood are bidirectional. In support of immune-to-brain pathways, sickness symptoms mediated by increases in circulating pro-inflammatory cytokines are consistent with symptoms of depression including fatigue, sleep disturbances, anxiety, negative mood, anhedonia, and loss of appetite [20]. Indeed, the experimental or clinical administration of cytokines or endotoxins results in a range of symptoms of depression [21]. For example, clinical administration of the pro-inflammatory cytokine interferon (IFN)- $\alpha$ in the treatment of cancer or chronic infection induces symptoms of major depressive disorder in $23 \%$ to $45 \%$ of all patients, with the degree of depression being positively related to dose and duration of treatment [22]. Epidemiologic evidence also shows that systemic inflammation predicts future risk for depressive symptoms and clinical episodes of depression in some [23-25], but not all longitudinal studies [26,27].

To examine the impact of peripheral inflammation on the central nervous system, recent attention has focused on whether immune-related patterns of brain activation are consistent with those that accompany clinical depression. Here, animal studies show that pro-inflammatory cytokines can penetrate the blood-brain barrier to stimulate the production of central pro-inflammatory cytokines by microglial cells in discrete brain regions that are involved in mood regulation and reward processing [20]. Recent human studies have employed randomized double-blind trials, exposing subjects to either immune stimulants (usually endotoxin) that generate low-grade systemic inflammatory responses or saline placebo and then comparing patterns of brain activation across the groups using functional magnetic resonance imagery. Using these methods, peripheral inflammation has been associated with negative mood states that are accompanied by increased activation of the subgenual anterior cingulate cortex (sgACC) and decreased connectivity of the sgACC with the amygdala, prefrontal cortex, nucleus accumbens, and superior temporal sulcus in response to emotional stimuli [28]. A similar pattern of heightened sgACC activity has been observed in response to IFN- $\alpha$ treatment [29] and during episodes of major depression, with activity returning to normative levels once symptoms remit [30]. Peripheral administration of endotoxin also reduces activity in the ventral striatum in response to a monetary reward task, a region of the brain implicated in the pleasurable effects of reward [31]. Taken together, these results raise the possibility that inflammation plays a role in the pathophysiology of the affective and anhedonic symptoms of depression [32].

In addition to immune-to-brain pathways, evidence also shows that negative mood states, stressful experiences, and antagonistic dispositions can activate peripheral physiologic pathways that modulate immune function. For example, negative moods are associated with activation of the hypothalamic-pituitary-adrenal (HPA) axis and the peripheral release of cortisol, along with increased activation of the sympathetic and decreased activation of the parasympathetic branches of the autonomic nervous system [33,34]. These physiologic responses modulate the activity of immune cells and are associated with increased production of pro-inflammatory cytokines [35] and levels of systemic inflammation [36]. Indeed, symptoms of depression have been positively associated with production of TNF- $\alpha$ by monocytes of healthy men and women $[37,38]$. Furthermore, some longitudinal studies show that symptoms of depression precede increases in systemic inflammation rather than result from them $[26,39,27]$.

\section{Conclusion}

In sum, converging evidence supports reciprocal pathways linking inflammation and the disruption of mood. It is likely that these pathways are part of a complex feedback loop that involves the neuroendocrine and 
immune systems and plays a role in both the modulation of peripheral inflammatory responses to stimuli and the maintenance of homeostatic balance. Further research examining specific symptoms and the central processes involved in these circuits is warranted to fully understand the role of inflammation in the pathophysiology of depression and of associated health morbidity. Evidence suggests that examining the impact of peripheral inflammation on central processes that play a role in specific symptoms of depression may point to novel targets for future intervention. For instance, Motivala $e t$ al. [40] found that changes in sleep during depression shared a stronger association with peripheral proinflammatory cytokines than other symptoms. Further research is also warranted to examine whether agerelated increases in systemic inflammation impact brain function and thus contribute to late-life depression.

\section{Authors' contributions}

BM conducted an up to date review of the relevant literature and wrote the initial draft of the manuscript. ALM edited the manuscript and made substantial revisions. AL read, contributed relevant research, and provided feedback on early and final versions of the manuscript. All authors read and approved the final manuscript.

\section{Authors' information}

ALM: Anna Marsland, Ph.D. is the Director of the Behavioral Immunology Laboratory and a member of the Biological and Health Psychology faculty at the University of Pittsburgh. Her expertise is in the field of

psychoneuroimmunology. BM: Berhane Messay is a second year graduate student in the Clinical and Biological/Health Psychology Programs at the University of Pittsburgh. AL: Alvin Lim is a second year graduate student in the Biological/Health Psychology Program at the University of Pittsburgh.

\section{Competing interests}

The authors declare that they have no competing interests.

Received: 2 November 2011 Accepted: 28 February 2012 Published: 28 February 2012

\section{References}

1. Wulsin $L R$, Singal $B M$ : Do depressive symptoms increase the risk for the onset of coronary disease? A systematic quantitative review. Psychosom Med 2003, 65:201-210.

2. Eaton WW, Armenian H, Gallo J, Pratt L, Ford DE: Depression and risk for onset of type II diabetes. A prospective population-based study. Diabetes Care 1996, 19:1097-1102.

3. Evans DL, Charney DS, Lewis L, Golden RN, Gorman JM, Krishnan KR, Nemeroff CB, Bremner JD, Carney RM, Coyne JC, Delong MR, FrasureSmith N, Glassman AH, Gold PW, Grant I, Gwyther L, Ironson G, Johnson RL, Kanner AM, Katon WJ, Kaufmann PG, Keefe FJ, Ketter T, Laughren TP, Leserman J, Lyketsos CG, McDonald WM, McEwen BS, Miller AH, Musselman D, et al: Mood disorders in the medically ill: scientific review and recommendations. Biol Psychiatry 2005, 58:175-189.

4. Koening HG: Depression in hospitalized older patients with congestive heart failure. Gen Hosp Psychiatry 1998, 20:29-43.

5. Katon WJ: Clinical and health services relationships between major depression, depressive symptoms, and general medical illness. Biol Psychiatry 54:216-226.

6. Fergusson DM, Goodwin RD, Horwood L: Major depression and cigarette smoking: results of a 21-year longitudinal study. Psychol Med 2003, 33:1357-1367.

7. Herbert TB, Cohen S: Depression and immunity: a meta-analytic review. Psychol Bull 1993, 113:472-486.
8. Irwin MR, Miller AH: Depressive disorders and immunity: 20 years of progress and discovery. Brain, Behav Immun 2007, 21:374-383.

9. Segerstrom SC, Miller GE: Psychological stress and the human immune system: a meta-analytic study of 30 years of inquiry. Psychol Bull 2004, 130:601-630.

10. Raison $\mathrm{CL}$, Capuron L, Miller AH: Cytokines sing the blues: inflammation and the pathogenesis of depression. Trends Immunol 2006, 27:24-31.

11. Black PH, Garbutt LD: Stress, inflammation and cardiovascular disease. $J$ Psychosom Res 2002, 52:1-23.

12. Maier SF, Watkins LR: Cytokines for psychologists: implications of bidirectional immune-to-brain communication for understanding behavior, mood, and cognition. Psychol Rev 1998, 105:83-107.

13. Dantzer R, O'Connor JC, Freund GG, Johnson RW, Kelley KW: From inflammation to sickness and depression: when the immune system subjugates the brain. Nat Rev Neurosci 2008, 9:46-56

14. Mohamed-Ali V, Goodrick S, Rawesh A, Katz DR, Miles JM, Yudkin JS, Klein S, Coppack SW: Subcutaneous adipose tissue releases interleukin-6, but not tumor necrosis factor-alpha, in vivo. J Clin Endocrinol Metab 1997, 82:4196-4120.

15. Rao KM, Pieper CS, Currie MS, Cohen HJ: Variability of plasma IL-6 and crosslinked fibrin dimers over time in community dwelling elderly subjects. Am J Clin Pathol 1994, 102:802-805.

16. Kiecolt-Glaser JK, Preacher KJ, MacCallum RC, Atkinson C, Malarkey WB, Glaser R: Chronic stress and age-related increases in the proinflammatory cytokine IL-6. Proc Natl Acad Sci USA 2003, 100:9090-9095

17. Ridker PM, Hennekens $\mathrm{CH}$, Buring JE, Rifai N: C-reactive protein and other markers of inflammation in the prediction of cardiovascular disease in women. N Engl J Med 2000, 342:836-843.

18. Dowlati Y, Hermann N, Swardfager W, Liu H, Sham L, Reim EK, Lanctot KL: A meta-analysis of cytokines in major depression. Biol Psychiatry 2010, 67:446-457.

19. Howren MB, Lamkin DM, Suls J: Associations of depression with Creactive protein, IL-1, and IL-6: a meta-analysis. Psychosom Med 2009, 71:171-186.

20. Miller $\mathrm{AH}$, Maletic $\mathrm{V}$, Raison $\mathrm{CL}$ : Inflammation and its discontents: the role of cytokines in the pathophysiology of major depression. Biol Psychiatry 2009, 65:732-741.

21. Reichenberg A, Yirmiya R, Schuld A, Kraus T, Haack M, Moraq A, Pollmächer T: Cytokine-associated emotional and cognitive disturbances in humans. Arch Gen Psychiatry 2001, 58:445-452.

22. Asnis G, De La Garza: Interferon-induced depression in chronic hepatitis C: a review of its prevalence, risk factors, biology, and treatment approaches. J Clin Gastroenterol 2006, 40:322-335.

23. Gimeno D, Kivimäki $M$, Brunner EJ, Elovainio $M$, De Vogli $R$, Steptoe $A$ Kumari M, Lowe GD, Rumley A, Marmot MG, Ferrie JE: Associations of Creactive protein and interleukin- 6 with cognitive symptoms of depression: 12-year follow-up of the Whitehall II study. Psychosom Med 2009, 39:413-423.

24. Milaneschi Y, Corsi AM, Penninx BW, Bandinelli S, Guralnik JM, Ferrucci L: Interleukin-1 receptor antagonist and incident depressive symptoms over 6 years in older persons: the InCHIANTI study. Biol Psychiatry 2009, 65:973-978.

25. Pasco JA, Nicholson GC, Williams $\downarrow$, Jacka FN, Henry MJ, Kotowicz MA, Schneider HG, Leonard BE, Berk M: Association of high-sensitivity Creactive protein with de novo major depression. Br J Psychiatry 2010, 197:372-377.

26. Duivis $H E$, de Jonge $P$, Penninx BW, Na BY, Cohen BE, Whooley MA: Depressive symptoms, health behaviors, and subsequent inflammation in patients with coronary heart disease: prospective findings from the heart and soul study. Am J Psychiatry 2011, 168:913-920.

27. Stewart JC, Rand KL, Muldoon MF, Kamarck TW: A prospective evaluation of the directionality of the depression-inflammation relationship. Brain, Behav Immun 2009, 23:936-944.

28. Harrison NA, Brydon L, Walker C, Gray MA, Steptoe A, Critchley HD: Inflammation causes mood changes through the alterations in subgenual cingulate activity and mesolimbic connectivity. Biol Psychiatry 2009, 66:407-414

29. Capuron L, Pagnoni G, Demetrashvili M, Woolwine BJ, Nemeroff CB, Berns GS, Miller AH: Anterior cingulate activation and error processing during interferon-alpha treatment. Biol Psychiatry 2010, 58:190-196. 
30. Drevets WC, Savitz J, Trimble M: The subgenual anterior cingulate cortex in mood disorders. CNS Spectr 2008, 13:663-681.

31. Eisenberger NI, Berkman ET, Inagaki TK, Rameson LT, Marshal NM, Irwin MR: Inflammation-induced anhedonia: endotoxin reduces ventral striatum responses to reward. Biol Psychiatry 2010, 68:748-754.

32. Krishnan V, Nestler EJ: The molecular neurobiology of depression. Nature 2008, 455:894-902

33. al'Absi M, Bongard S: Neuroendocrine and behavioral mechanisms mediating the relationship between anger expression and cardiovascular risk: assessment considerations and improvements. J Behav Med 2006, 29:573-591.

34. Suarez EC, Kuhn CM, Schanberg Sm, Williams RB Jr, Zimmermann EA: Neuroendocrine, cardiovascular, and emotional responses of hostile men: the role of interpersonal challenge. Psychosom Med 1998, 60:78-88,

35. Marsland AL, Gianarod PJ, Prather AA, Jennings JR, Newmann SA, Manuck SB: Stimulated production of proinflammatory cytokines covaries inversely with heart rate variability. Psychosom Med 2007, 69:709-716.

36. Miller GE, Stetler CA, Carney RM, Freedland KE, Banks WA: Clinical depression and inflammatory risk markers for coronary heart disease. Am J Cardiol 2002, 90:1279-1283.

37. Suarez EC, Krishnan RR, Lewis JG: The relation of severity of depressive symptoms to monocyte-associated proinflammatory cytokines and chemokines in apparently healthy men. Psychosom Med 2003, 65:362-368.

38. Suarez EC, Lewis JG, Krishnan RR, Young KH: Enhanced expression of cytokines and chemokines by blood monocytes to in vitro lipopolysaccharide stimulation are associated with hostility and severity of depressive symptoms in healthy women. Psychoneuroendocrinology 2004, 29:1119-1128.

39. Deverts DJ, Cohen S, DiLillo VG, Lewis CE, Kiefe C, Whooley M, Matthews KA: Depressive symptoms, race, and circulating C-reactive protein: the coronary artery risk development in young adults (CARDIA) study. Psychosom Med 2010, 72:734-741.

40. Motivala SJ, Sarfatti A, Olmos L, Irwin MR: Inflammatory markers and sleep disturbances in major depression. Psychosom Med 2005, 67:187-194.

doi:10.1186/PREACCEPT-1461493759628561

Cite this article as: Messay et al:: Current understanding of the bi-

directional relationship of major depression with inflammation. Biology of Mood \& Anxiety Disorders 2012 2:4.

\section{Submit your next manuscript to BioMed Central and take full advantage of:}

- Convenient online submission

- Thorough peer review

- No space constraints or color figure charges

- Immediate publication on acceptance

- Inclusion in PubMed, CAS, Scopus and Google Scholar

- Research which is freely available for redistribution

Submit your manuscript at www.biomedcentral.com/submit 